\title{
sciendo
}

Current Issues in Pharmacy and Medical Sciences

Formerly ANNALES UNIVERSITATIS MARIAE CURIE-SKIODOWSKA, SECTIO DDD, PHARMACIA

journal homepage: http://www.curipms.umlub.pl/

\section{Assessment of safety and effectiveness of oral morphine on patients attending pain and palliative care: a study on Indian population}

\author{
Sreelakshmi Jayan ${ }^{1}$, Stephy Stephen ${ }^{1}$, Kevin Tom Koshy ${ }^{1}$, \\ Nikhil John Abraham ${ }^{1}$, Sunitha Daniel ${ }^{2}$, Anila K N ${ }^{3 *}$ •
}

\footnotetext{
${ }^{1}$ Department of Pharmacy Practice, Amrita School of Pharmacy, Kochi, Kerala, Amrita Vishwa Vidyapeetham, India

${ }^{2}$ Department of Pain and Palliative, Amrita Institute of Medical Science and Research Centre, Kochi, Kerala, Amrita Vishwa Vidyapeetham, India

${ }^{3}$ Department of Pharmacy Practice, Amrita School of Pharmacy, Kochi, Kerala, Amrita Vishwa Vidyapeetham, India
}

\section{ARTICLE INFO}

Received 02 August 2019

Accepted 04 June 2020

\section{Keywords:}

palliative care,

opioids,

pain,

morphine,

cancer,

non cancer.

\begin{abstract}
Opioid analgesics remain the corner stone of effective management of moderate to severe pain. Morphine in its oral and parenteral form is one of the most affordable options left to treat severe cancer pain in most Palliative centres in India. The main objective of our study was to assess the safety and effectiveness, as well as the prescribing pattern of immediate release oral morphine on the Indian population attending Pain and Palliative Care in a multi-speciality hospital. Within the sample population, $74.8 \%$ of all patients achieved a pain score reduction of less than or equal to 3 within the $72^{\text {nd }}$ hour. Although the mean baseline pain score was similar in the cancer $(8.23 \pm 0.75)$ and the non-cancer $(8.26 \pm 0.98)$ group, the mean pain score at the 24 th and 72 nd hours were significantly different $(5.6 \pm 1.29$ in cancer and $5.09 \pm 1.26$ in the non-cancer group within the $24^{\text {th }}$ hour, followed by $3.66 \pm 1.479$ and $3.12 \pm 0.88$ after the $72^{\text {nd }}$ hour, respectively). The majority of the patients (58.3\%) were prescribed at a frequency of $5 \mathrm{mg}$ every $4^{\text {th }}$ hourly, with double dose at bedtime. A similar prescribing trend was seen in both the cancer and non-cancer groups. Moreover, 14 patients underwent dose escalation - with 12 belonging to the cancer group, while 11 patients falling under the cancer group required a switch to different therapy. The major adverse drug reactions (ADR) observed in both study groups were constipation (89.2\%), fatigue (37.4\%), dry mouth (36\%) and nausea/ vomiting (23\%). The severity of nausea/vomiting and sleepiness was higher in the cancer group whereas itching was more predominant among the non-cancer group.
\end{abstract}

\section{INTRODUCTION}

Uncontrolled pain irrespective of its nature has a devastating impact on the physical, emotional, social and well-being of the patient and their families [1]. It simply cripples the quality of life and generally hinders any progress. For this reason, it is essential to relieve them from such deteriorating conditions through appropriate pain management. Palliative care is one such multidisciplinary medical speciality that specialises in providing pain management and thereby improves the quality of life for the patients who are inflicted with terminal, as well as life threatening diseases [2,3].

\footnotetext{
* Corresponding author

e-mail: anilakn@aims.amrita.edu
}

Currently, the principles of pain management place emphasis on providing adequate pain management and preventing its recurrence, achieving pain relief with minimum side effects and improving the quality of life, by following a systematic approach of treatment of pain through applying WHO's analgesic ladder and adjuvant therapy, along with analgesic pain medications [4]. Opioids have always remained the mainstay of treatment for managing severe pain that is not adequately addressed by non-opioid analgesics like NSAIDs [5]. Among the opioid analgesics, morphine has always remained the prototype opioid analgesic for moderate to severe pain and is considered the standard 'step 3'opioid analgesic for effective pain management. Oral morphine is available as both immediate release 
and extended release formulation. In our study, immediate release oral morphine was used. This is usually given every $4^{\text {th }}$ hourly.

In the past two decades there has been a massive increase in the number of opioid prescription (as prescribed daily opioid doses) and overall opioid availability. Intersecting with this upward trajectory of opioid use are the increasing trends in opioid related adverse drug reactions (ADRs). Hence, through this study, we intend to evaluate the side effect profile and effectiveness of opioids in Palliative Care.

Morphine as an oral and parenteral preparation is one of the most affordable option left to treat severe cancer pain in most Palliative centres in India. Our study can provide an insight to the current clinical scenario and assess if any difference is observed in side effect profile among cancerous and non-cancerous patients. The prescribing patterns of oral morphine in Palliative Care settings of our hospitals in India have not yet studied. No similar published literatures on Indian populations were available that assesses the effectiveness and safety of immediate release oral morphine in patients attending Palliative Care. Most reports about the prescribing pattern of patients receiving oral morphine were written predominantly about Western population, whereas reports of Indian populations are limited [6]. Our study could, therefore, act as a basis for establishing morphine as an effective short term therapy, as well as a means to overcome opioid phobia commonly seen while prescribing.

The primary focus of our study was to assess the safety and effectiveness of immediate release oral morphine tablets in cancer and non-cancer groups of patients attending Pain and Palliative Care in our hospital, and to analyse the prescription pattern of the same. We also aspired to evaluate whether the immediate release oral morphine manufactured locally provides round the clock pain relief. The goal was to achieve a better balance in addressing the treatment of pain, while keeping the side effects at bay, hence, enabling functional restoration in the patient. A further goal is to fill the current gap in our knowledge regarding the side effect profile and effectiveness of oral morphine among various groups of patients attending Palliative Care.

\section{METHODOLOGY}

The proposed study was initiated only after being approved by the institutional ethics committee. A signed informed consent was obtained from all the study subjects prior to the initiation of the study. The study was conducted in the department of Pain and Palliative Care of a multispeciality hospital from August 2017 to May 2018 with 6 months of data collection. Patients aged above 18 years and receiving oral morphine for the first time (opioid naive) attending Pain and Palliative Care were enrolled in the study. Patients with aphasia, cognitive impairment, hepatic and renal impairment, unconscious and delirious were excluded from the study.

This was an observational longitudinal single centred study with a 6 months data collection period. A sample size of 139 patients who had received immediate release oral morphine were included in the study following screening based on the inclusion and exclusion criteria. Data was collected by personal interview with the patients and also by evaluating patient medical records and the health information system (AHIS) - the electronic database containing all patient related information used in the hospital. Patients were assessed for their improvement in pain control, as well as safety of therapy indicated by the occurrence of ADRs. Achievement of round-the-clock pain relief following immediate release oral morphine therapy which was locally manufactured were also examined. We also attempted to segregate the study subjects into cancer and non-cancer groups on the basis of their clinical diagnosis so as to discover any difference in the outcome.

\section{OUTCOME MEASURES}

A data collection form combined need to be added with a detailed questionnaire was used to record and assess various pain outcome measures. It contained demographic details and questions regarding the character, nature and duration of pain, pain intensity rating, prescription pattern and other details relevant to the study. The intensity of pain was measured using a 10 point numerical pain rating scale where the patients were asked to rate their pain in a scale of 0 (no pain) to 10 (worst possible pain). A baseline pain score before therapy and subsequent pain score at $24^{\text {th }}$, 48th and $72^{\text {nd }}$ hour till the pain score was reduced to $\leq 3$ were recorded. The reduction in pain score from baseline to 3 was employed as the outcome measure for pain relief, which, in turn, provided an indication as to whether the therapy was effective.

The prescribing pattern of oral morphine was ascertained by analysing the date obtained from patient medical records. All the oral morphine prescriptions of the study subjects were reviewed and analysed. Details regarding the dose, frequency, duration, as well as switch over therapy to IV morphine or other opioids and those who required dose escalations from their initial prescribed dose were assessed. Adjuvant analgesics given along with morphine were also recorded.

A Numerical Opioid Side Effect (NOSE) assessment tool was used to evaluate the safety of oral morphine therapy by establishing the side effect profile, along with their severity, by rating in a scale of 0 (not present) to 10 (as bad as one can imagine). For the purpose of the study, the rating scale was further categorized into mild (0-3), moderate (4-6) and severe (7-10). The Naranjo causality assessment scale was employed to discover possible causal relationship between the drug and the ADRs observed, as this is a simple questionnaire that assigns a probability score and classifies it as definite (>9), probable (5-8), possible (1-4), doubtful (0).

\section{STATISTICAL ANALYSIS}

In this study, a sample size of 139 patients were selected. (Confidence Interval - 95\%, level of significance - 5\%, prevalence, $\mathrm{p}-0.1)$. Statistical tests used for analysing the sample included:

1. Students independent $t$ test for comparison of demographic variables

2. Chi square test for testing the independence of attributes 
3. Mann Whitney $U$ test for mean changes of continuous variables between two groups.

Statistical analysis was performed using IBM SPSS version 20.0 software. To test the statistical significance of the differences of the categorical variables between cancer and non-cancer patients, Chi-square test was used. To test the statistical significance of the mean changes of continuous variables between two groups of independent samples, t-test/Mann Whitney U test was employed.

\section{RESULT}

\section{Demographic and disposition factors}

Within the study period, a total of 139 patients prescribed with immediate release oral morphine were selected for our study. Our study sample comprised of 75 (54\%) in-patients and 64 (46\%) out-patients, among which, 92 (66\%) were males and 47 (33.8\%) were females. The various demographic details are shown in Table 1. Patients were categorized into cancerous and non-cancerous groups based on the aetiology of pain, with $104(74.8 \%)$ belonging to the former and $35(25.2 \%)$ to the latter. Within the cancerous group, $86(82.69 \%)$ had solid tumour and $18(17.39 \%)$ had blood malignancies. According to initial data, 61 (70.9\%) patients who received oral morphine therapy were at stage 4 cancer, followed by $15(17.4 \%)$ at stage $3,8(9.3 \%)$ at stage 2 and $2(2.3 \%)$ at stage 1 cancer. The non-cancerous group consisted of cases such as Rheumatoid arthritis (RA), Peripheral vascular occlusive disease (PVOD), Systemic lupus erythematosus (SLE), fracture and post-operative pain. The mean age of patients in the cancer group was $58.05 \pm 13.45$, while in the non-cancer group it was 58.51 15.9 .

Table 1. Demographic details

\begin{tabular}{|l|c|}
\hline \multicolumn{1}{|c|}{ Characteristics } & $\begin{array}{c}\text { Sample Population } \\
(\mathrm{n}=139)\end{array}$ \\
\hline Age ( years) & \\
Mean (SD) & $58.17(14.0533)$ \\
Range (minimum to maximum) & $20-83$ \\
\hline Gender, $\mathbf{n}$ (\%) & \\
Male & $92(66.2)$ \\
Female & $47(33.8)$ \\
\hline Departments, $\mathbf{n}$ (\%) & \\
Oncology and Haematology & $106(76.3)$ \\
Orthopaedics & $13(9.4)$ \\
CVTS & $12(8.6)$ \\
Neurology & $3(2.2)$ \\
Rheumatology & $2(1.4)$ \\
GI Surgery & $2(1.4)$ \\
Endocrinology & $1(0.7)$ \\
\hline Comorbid conditions, $\mathbf{n}(\%)$ & \\
Hypertension & $51(39.2)$ \\
DM & $45(34.6)$ \\
DLP & $10(7.7)$ \\
COPD/Asthma & $7(5.4)$ \\
CAD & $6(4.6)$ \\
Hypothyroidism & $4(3.1)$ \\
Others & $7(5.4)$ \\
\hline
\end{tabular}

\section{Pain and its characteristics:}

Of 139 patients, 73 (52.5\%) had acute pain, whereas $66(47.5 \%)$ had chronic pain that had persisted for more than one month. Chronic pain was more prevalent within cancer patients, i.e $64(61.5 \%)$, whereas acute pain was higher among the non-cancer group, i.e 33 (94.3\%). Of both groups, 112 patients $(80.6 \%)$ had pain for a duration of 1 month or less, whereas $26(18.7 \%)$ had pain for more than a few months. While analysing the nature of pain, $60(43.2 \%)$ described pain as always/often present. Note: a reduction of pain score to 3 or less within the $72^{\text {nd }}$ hour of morphine therapy were used to guide our decision about pain reduction and its adequate control.

When asked to describe their pain as tingling, burning, throbbing, aching, radiating, numbing and stabbing, 87 (40.5\%) described pain as aching, while 68 (31.6\%) described it as throbbing. Moreover, 33 (18.1\%) patients complained about pain in their abdomen. This was found to be highest among the study population, followed by $28(15.3 \%)$ in thoracic and $27(14.8 \%)$ in the lower limbs. On comparing groups, 29 (20\%) of the cancer group exhibited abdominal pain and $16(32 \%)$ of the non-cancer group considered lower limb pain as the major pain location.

\section{Prescription pattern}

Total daily dose of immediate release oral morphine ranged from 5 to $120 \mathrm{mg}$, with $30 \mathrm{mg}(57.6 \%)$ being the most widely prescribed. The majority of the patients, i.e. $81(58.3 \%)$, were prescribed in the frequency of $5 \mathrm{mg}-$ $-5 \mathrm{mg}-5 \mathrm{mg}-5 \mathrm{mg}-10 \mathrm{mg}$ and $19(13.7 \%)$ patients in the frequency $2.5 \mathrm{mg}-2.5 \mathrm{mg}-2.5 \mathrm{mg}-2.5 \mathrm{mg}-5 \mathrm{mg}$ (Table 2). Mean total daily dose $(\mathrm{mg})$ for cancer and non-cancer patients were found to be $31.56 \pm 16.22$ and $29.63 \pm 16.12$, respectively.

Table 2. Frequency of morphine prescribed in the sample population

\begin{tabular}{|l|c|c|c|}
\hline \multicolumn{1}{|c|}{ Frequency of morphine } & $\begin{array}{c}\text { Total dose } \\
(\mathrm{mg})\end{array}$ & $\begin{array}{c}\text { No. of } \\
\text { patients } \\
(\mathrm{n}=139)\end{array}$ & $\begin{array}{c}\text { Percentage } \\
(\%)\end{array}$ \\
\hline $0-0-5 \mathrm{mg}$ & 5 & 1 & 0.7 \\
\hline $2.5 \mathrm{mg}-2.5 \mathrm{mg}-2.5 \mathrm{mg}-2.5 \mathrm{mg}$ & 10 & 3 & 2.2 \\
\hline $2.5 \mathrm{mg}-2.5 \mathrm{mg}-2.5 \mathrm{mg}-2.5 \mathrm{mg}-2.5 \mathrm{mg}$ & 12.5 & 2 & 1.4 \\
\hline $5 \mathrm{mg}-5 \mathrm{mg}-5 \mathrm{mg}$ & 15 & 1 & 0.7 \\
\hline $2.5 \mathrm{mg}-2.5 \mathrm{mg}-2.5 \mathrm{mg}-2.5 \mathrm{mg}-5 \mathrm{mg}$ & 20 & 19 & 13.7 \\
\hline $5 \mathrm{mg}-5 \mathrm{mg}-5 \mathrm{mg}-5 \mathrm{mg}$ & 20 & 7 & 5.1 \\
\hline $5 \mathrm{mg}-5 \mathrm{mg}-5 \mathrm{mg}-5 \mathrm{mg}-5 \mathrm{mg}$ & 25 & 4 & 2.9 \\
\hline $5 \mathrm{mg}-5 \mathrm{mg}-5 \mathrm{mg}-10 \mathrm{mg}$ & 25 & 1 & 0.7 \\
\hline $5 \mathrm{mg}-5 \mathrm{mg}-5 \mathrm{mg}-5 \mathrm{mg}-10 \mathrm{mg}$ & 30 & 81 & 58.3 \\
\hline $7.5 \mathrm{mg}-7.5 \mathrm{mg}-7.5 \mathrm{mg}-7.5 \mathrm{mg}-10 \mathrm{mg}$ & 40 & 1 & 0.7 \\
\hline $10 \mathrm{mg}-10 \mathrm{mg}-10 \mathrm{mg}-20 \mathrm{mg}$ & 50 & 1 & 0.7 \\
\hline $10 \mathrm{mg}-10 \mathrm{mg}-10 \mathrm{mg}-10 \mathrm{mg}-20 \mathrm{mg}$ & 60 & 15 & 10.8 \\
\hline $20 \mathrm{mg}-20 \mathrm{mg}-20 \mathrm{mg}-20 \mathrm{mg}$ & 80 & 1 & 0.7 \\
\hline $15 \mathrm{mg}-15 \mathrm{mg}-15 \mathrm{mg}-15 \mathrm{mg}-30 \mathrm{mg}$ & 90 & 1 & 0.7 \\
\hline $20 \mathrm{mg}-20 \mathrm{mg}-20 \mathrm{mg}-20 \mathrm{mg}-40 \mathrm{mg}$ & 120 & 1 & 0.7 \\
\hline
\end{tabular}

Mean duration of oral morphine therapy among the 139 patients were found to be $13.75 \pm 8.38$ days. The minimum and maximum duration of therapy was seen to be 2 and 40 days, respectively (Table 3 ). The majority of cancer patients, i.e. $40(38.5 \%)$ underwent a duration of 8-14 days of therapy, while non-cancer patients, i.e. 15 (42.9\%) underwent 1-7 days of therapy. Oral morphine therapy for more than 28 days were seen in $18(17.3 \%)$ cancer patients, and was less predominant among the non-cancer group. 
Table 3. Dose escalation from initial prescribed dose in patients recieving oral morphine

\begin{tabular}{|c|c|c|c|c|c|}
\hline Initial dose frequency & $\begin{array}{l}\text { Total dose } \\
\text { (mg) }\end{array}$ & Frequency after dose escalation & $\begin{array}{c}\text { Total dose } \\
(\mathrm{mg})\end{array}$ & $\begin{array}{c}\text { No. of } \\
\text { patients } \\
(n=139)\end{array}$ & $\begin{array}{c}\text { Percentage } \\
(\%)\end{array}$ \\
\hline \multicolumn{4}{|l|}{ No dose escalation needed } & 125 & 89.9 \\
\hline $5 m g-5 m g-5 m g-5 m g-10 m g$ & 30 & $10 \mathrm{mg}-10 \mathrm{mg}-10 \mathrm{mg}-10 \mathrm{mg}-20 \mathrm{mg}$ & 60 & 7 & 5.2 \\
\hline $5 m g-5 m g-5 m g-5 m g$ & 20 & $10 \mathrm{mg}-10 \mathrm{mg}-10 \mathrm{mg}-10 \mathrm{mg}-20 \mathrm{mg}$ & 60 & 1 & 0.7 \\
\hline $5 m g-5 m g-5 m g$ & 15 & $5 m g-5 m g-5 m g-5 m g$ & 20 & 1 & 0.7 \\
\hline $5 m g-5 m g-5 m g-5 m g$ & 20 & $10 \mathrm{mg}-10 \mathrm{mg}-10 \mathrm{mg}-10 \mathrm{mg}$ & 40 & 1 & 0.7 \\
\hline $2.5 \mathrm{mg}-2.5 \mathrm{mg}-2.5 \mathrm{mg}-2.5 \mathrm{mg}-2.5 \mathrm{mg}$ & 12.5 & $5 m g-5 m g-5 m g-5 m g-10 m g$ & 30 & 1 & 0.7 \\
\hline $2.5 \mathrm{mg}-2.5 \mathrm{mg}-2.5 \mathrm{mg}-2.5 \mathrm{mg}-5 \mathrm{mg}$ & 15 & $5 m g-5 m g-5 m g-5 m g-10 m g$ & 30 & 1 & 0.7 \\
\hline $7.5 \mathrm{mg}-7.5 \mathrm{mg}-7.5 \mathrm{mg}-7.5 \mathrm{mg}-10 \mathrm{mg}$ & 40 & $10 \mathrm{mg}-10 \mathrm{mg}-10 \mathrm{mg}-10 \mathrm{mg}-20 \mathrm{mg}$ & 60 & 1 & 0.7 \\
\hline $20 \mathrm{mg}-20 \mathrm{mg}-20 \mathrm{mg}-20 \mathrm{mg}$ & 80 & $20 \mathrm{mg}-20 \mathrm{mg}-20 \mathrm{mg}-20 \mathrm{mg}-20 \mathrm{mg}-20 \mathrm{mg}$ & 120 & 1 & 0.7 \\
\hline
\end{tabular}

Although the mean baseline pain score was similar in cancer $(8.23 \pm 0.75)$ and non-cancer $(8.26 \pm 0.98)$ groups, the mean pain scores at the $24^{\text {th }}$ and $72^{\text {nd }}$ hours were significantly different. This was $5.6 \pm 1.29$ in the cancer and $5.09 \pm 1.26$ in the non-cancer groups within $24^{\text {th }}$ hours of oral morphine therapy, while it was $3.66 \pm 1.479$ in the
Out of 139 patients, 14 (10.07\%) underwent dose escalation from their initial prescribed dose due to insufficient pain relief, out of which $12(11.5 \%)$ belonged to the cancer group, while only $2(5.7 \%)$ belonged to the non-cancer group (Table 3). Furthermore, $11(7.9 \%)$ patients from the study group required a switch over from oral morphine therapy to intravenous morphine/other opioids therapy. All the above mentioned 11 patients belonged to the cancer group.

In a majority of the patients, oral morphine was prescribed as 4 th hourly, although $6^{\text {th }}$ hourly, $8^{\text {th }}$ hourly and once a day frequency were given, yet these regimes accounted for in less than $5 \%$ of the total study population. In contrast, $99(95.2 \%)$ within the cancer group and $33(34.3 \%)$ within the non-cancer group were prescribed oral morphine as $4^{\text {th }}$ hourly along with a double dose at bedtime (Table 3 ). Adjuvant treatment with drugs like paracetamol, pregabalin, corticosteroids and benzodiazepines were frequently prescribed in our study, with paracetamol (36.5\%) being prescribed highest among the patients, followed by pregabalin $(28.4 \%)$ and corticosteroids (10.8\%).

\section{Effectiveness and safety}

Mean baseline pain score was found to be $8.24 \pm 0.813$, whereas mean pain score at $24^{\text {th }}$ and $72^{\text {nd }}$ hours was $5.47 \pm 1.304$ and $3.52 \pm 1.368$, respectively. Out of 139 patients, $104(74.8 \%)$ patients had their pain score reduced to 3 within the $72^{\text {nd }}$ hour of morphine administration. On comparing the cancer and non-cancer groups, $74(71.2 \%)$ of the cancer patients had achieved pain score reduction $\leq 3$, whereas 30 $(85.7 \%)$ non-cancer patients achieved the same score within $72^{\text {nd }}$ hours of oral morphine therapy. The mean percentage difference in pain score from baseline to $24^{\text {th }}$ hour was found to be $31.68 \pm 15.612 \%$ and $38.18 \pm 14.2 \%$ in cancer and noncancer groups, respectively, while the mean percentage difference in pain score from baseline to $72^{\text {nd }}$ hour was found to be $55.28 \pm 18.15 \%$ in the cancer group and $62 \pm 11.34 \%$ in the non-cancer group $(\mathrm{p}<0.020, \mathrm{p}<0.047$ respectively) (Table 4).

Table 4. Mean percentage difference in pain score among cancer and non cancer groups

\begin{tabular}{|c|c|c|c|c|c|}
\hline \multicolumn{2}{|l|}{ Group } & $\mathrm{n}$ & $\begin{array}{c}\text { Mean } \\
\text { difference (\%) }\end{array}$ & $\begin{array}{c}\text { Std. } \\
\text { Deviation }\end{array}$ & $\mathrm{p}$ Value \\
\hline \multirow{2}{*}{ Baseline with $24^{\text {th }} \mathrm{hr}$} & Cancer & 104 & 31.68 & 15.61 & \multirow{2}{*}{0.020} \\
\hline & Non Cancer & 35 & 38.18 & 14.20 & \\
\hline \multirow{2}{*}{ Baseline with $72^{\text {nd }} \mathrm{hr}$} & Cancer & 99 & 55.28 & 18.15 & \multirow{2}{*}{0.047} \\
\hline & Non Cancer & 34 & 62.00 & 11.34 & \\
\hline
\end{tabular}

cancer group and $3.12 \pm 0.88$ in the non-cancer group after the $72^{\text {nd }}$ hour (Figure 1). On comparing gender and pain relief within the $72^{\text {nd }}$ hour, $75 \%$ of the male patients and $74.5 \%$ of the female patients achieved significant pain relief within 72 hours. The result were, however, statistically non-significant, confirming no significant difference in pain relief between males and females.

The major side effect observed in patients undergoing oral morphine therapy were constipation (89.2\%), fatigue (37.4\%), dry mouth (36\%) and nausea/vomiting (23\%) (Figure 2). On the basis of intensity, a higher proportion of cancer patients experienced severe nausea/vomiting (7.7\%) and sleepiness (5.7\%), whereas itching was slightly higher in non-cancer patients (2.9\%). On comparing the Naranjo causality assessment in cancer and non-cancer groups, constipation was found to be the most possible ADR of morphine in both the groups, followed by fatigue, nausea/vomiting, dry mouth and sleepiness (Figure 3 and 4).

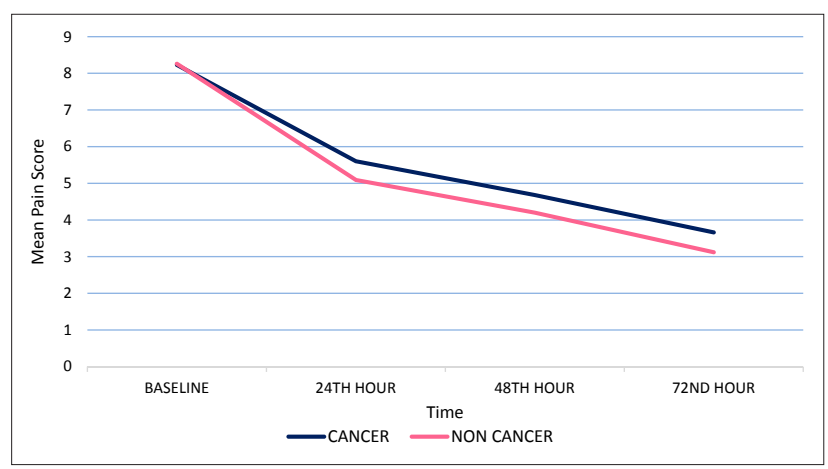

Figure 1. Mean pain score in cancer and non cancer groups

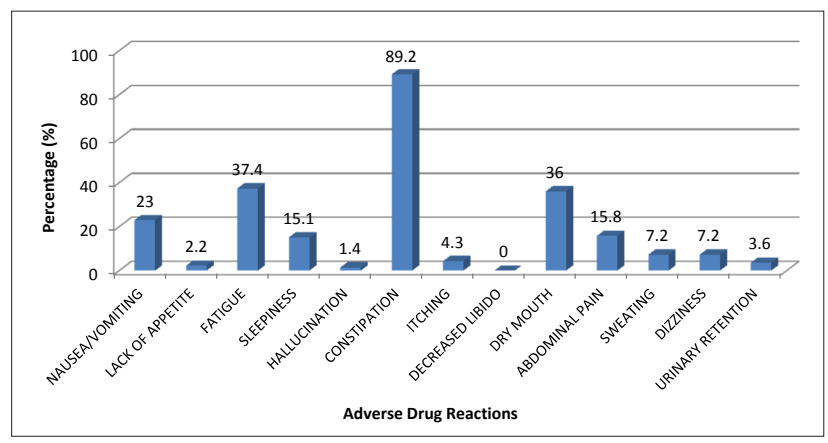

Figure 2. Adverse drug reactions in patients receiving oral morphine 


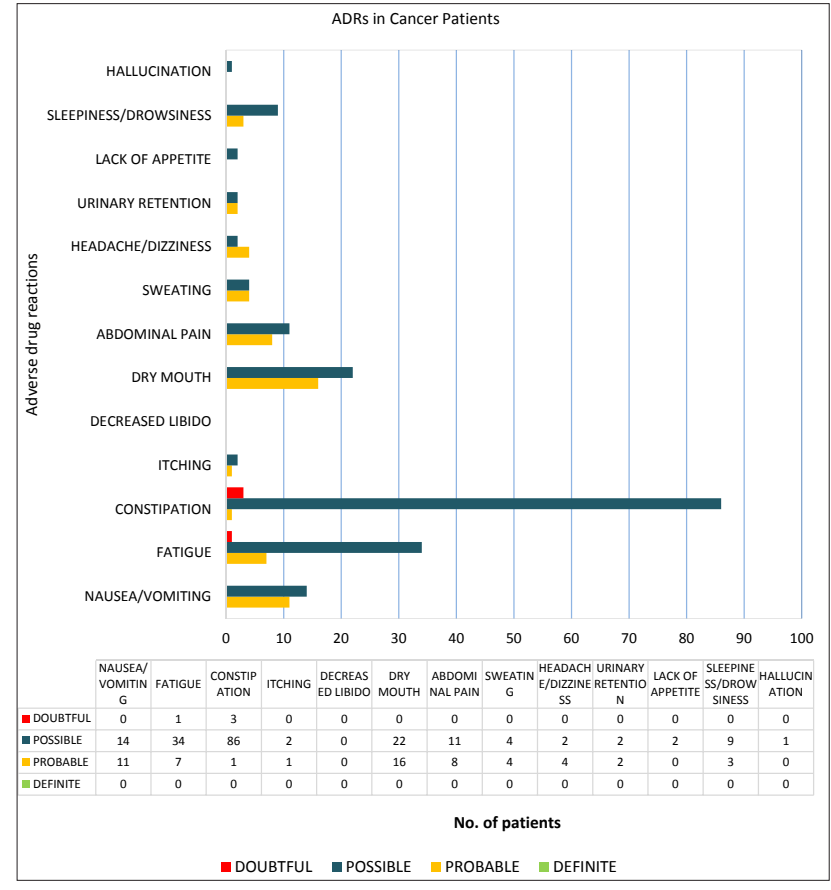

Figure 3. Naranjo causality assessment of ADR in cancer patients

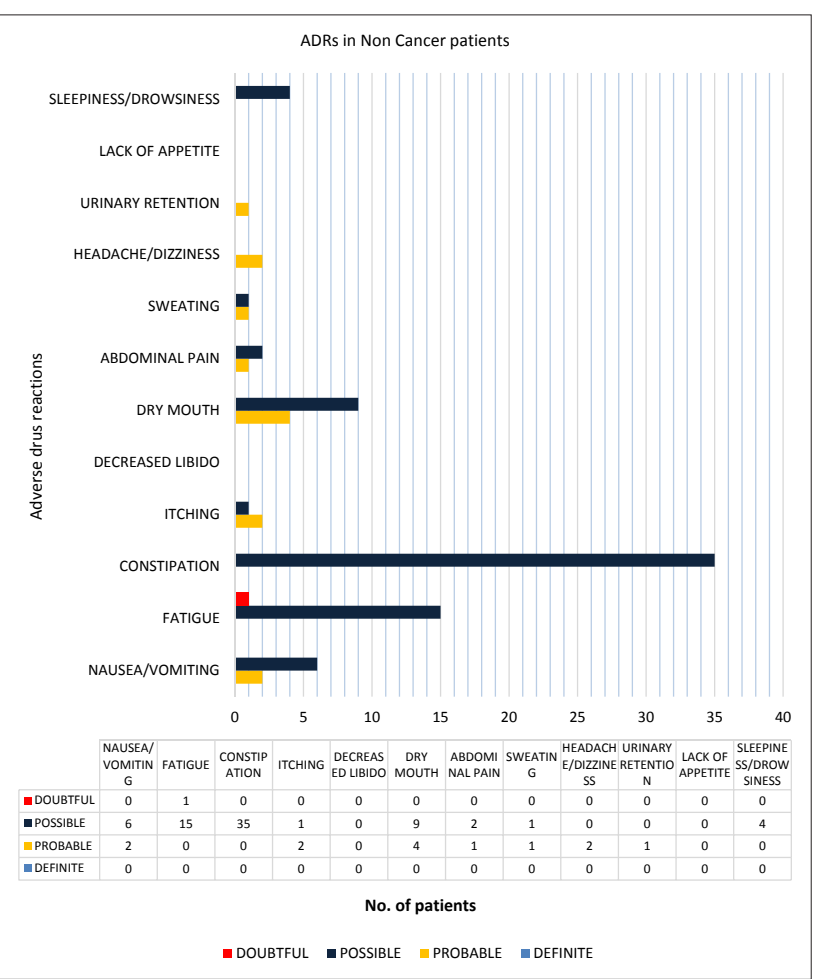

Figure 4. Naranjo causality assessment of ADR in non cancer patients

\section{DISCUSSION}

Falling under the WHO analgesic ladder step 3, morphine has been proven to be an effective opioid in the treatment of moderate to severe pain ${ }^{4}$. Although morphine has wellestablished results in cancer and non-cancer pain, prior to our study, we were unaware of any significant difference among the two groups regarding effectiveness and safety, especially in the Indian population. Moreover, although there are plenty of established studies on Western populations regarding the effectiveness and safety of oral morphine, there was a lack of sufficient evidence in the Indian population. Hence, we, through our study, have tried to analyse and understand possible differences. Moreover, we made an effort to provide an internal comparison between cancer and non-cancer groups.

The most common location of pain in our sample population was in the abdominal region, followed by thoracic and lower limbs. Within the cancer group, a majority of patients had pain in their abdominal region, whereas in the non-cancer group it was in lower limbs. Since our sample population consists of a major fraction of cancer patients at stage 4 metastasis, higher complaints of abdominal and thoracic pain could be the result of multi organ involvement. Regarding the non-cancer patients, a higher proportion had cases of Peripheral vascular occlusive disease (PVOD) and this could have contributed to the higher complaints of lower limb pain.

We observed a higher percentage of solid tumour cases among our sample population than of cases with blood malignancy. This could be due to the lower pain prevalence seen within blood tumours. This is further supported by a study conducted by Breivik $\mathrm{H}$ et al. with an aim to increasing the understanding of cancer-related pain and treatment across Europe [7]. Their study included a wide range of cancer cases, including both solid and haematological cancers. Herein, on observing the pain prevalence among different cancer cases, $<75 \%$ were observed in leukemia cases [7]. However, a limited number of haematological cases being presented with symptoms of pain, as well as the attitude of the referring haematologist also needs to be considered.

While analysing the prescription pattern of oral morphine in our sample population, the total daily dose ranged from $5-120 \mathrm{mg}$, with $57.6 \%$ of the sample population receiving $30 \mathrm{mg}$ as total daily dose. This was consistent with the findings of a study conducted by James Brown et al. where $83 \%$ of all patients received a total daily dose of 30-120 mg [8]. Most of the patients had concurrently received a double dose at bed time so as to prevent sleep disturbances due to lack of pain control. In addition, a majority of the patients were prescribed at a frequency of $4^{\text {th }}$ hourly. All the patients received laxative as a prophylactic measure for opioid-induced constipation [9-11].

In another study conducted by Elumelu et al, they analysed 736 oral morphine prescription sheets in a Nigerian tertiary hospital for a period of 6 months. Here, the mean duration of therapy was found to be $12.53 \pm 6.96$ days, with $77.2 \%$ of the patients being prescribed every $4^{\text {th }}$ hourly [12]. Following the WHO opioid prescribing guideline, morphine is given as a step 3 analgesic for moderate to severe pain and should generally be given in adjunctive with non-opioid analgesics. As per the guideline, the initial dose of $5 \mathrm{mg}$ every 4 hours with a double dose at bedtime should be followed. Such opioid therapy should be given along with a stimulant laxative as prophylaxis [13]. On comparison of prescribing pattern between cancer and noncancer groups, the mean total daily dose, as well as duration of oral morphine therapy in cancer patients were found to be slightly higher. Even though morphine is effective 
in non-cancer patients, long term therapy is not advisable due increased risks of side effects.

Adjuvant analgesics like paracetamol, pregabalin, corticosteroids and benzodiazepines were frequently prescribed in our study. Adjuvant/non-opioid analgesics are generally prescribed along with morphine therapy as per the prescribing guideline[13-18]. Such adjuvant analgesics can enhance the effect of opioids in morphine resistant/neuropathic pain[19-21]. In addition to the above mentioned reasons, such adjuvant analgesics possess a dosing flexibility and when given appropriately might also assist in reducing opioid-related side effects [22].

Doses were escalated in patients not achieving adequate pain relief with the usual initial dose. Out of the 14 patients in which this was indicated, 7 patients underwent a dose escalation from an initial total dose of $30 \mathrm{mg}$ to $60 \mathrm{mg}$. For the remaining patients, a similar dose escalation pattern could not be observed which could be attributed to varying factors like patient frailty, risk of sedation, opioid phobia seen among the patients, etc [23]. For such patients, individualized prescribing patterns based on clinical judgement and experience were followed, rather than general guidelines for dose escalation. Genetic variations at the gene encoding the $\mu$ opioid receptor might also contribute to variability in patients' response to morphine [24]. In our study, 11 patients out of 139 required switch over from oral morphine therapy to intravenous morphine/other opioids therapy as a result of inadequate pain relief. This could be attributed to psychological factors and morphine non-responsive pain, as well as their genetic makeup [25].

To evaluate the effectiveness of oral morphine therapy, in our study, patients were asked to rate their pain intensity using a numerical pain scale before the beginning of morphine therapy. This was recorded as baseline pain score. Subsequently, their pain scores at $24^{\text {th }}, 48^{\text {th }}$ and $72^{\text {nd }}$ hours were taken and analysed. A reduction of pain score to 3 or less within the 72 nd hour of morphine therapy were used to guide our decision about pain reduction and its adequate control. Accordingly, $74.8 \%$ of our study population achieved satisfactory pain alleviation by showing a reduction in pain score below 3 by the $72^{\text {nd }}$ hour.

A significant difference $(0.03, \mathrm{p}<0.05)$ was observed on comparing the reduction in pain score among the cancer and non-cancer groups. Although the mean baseline pain score was similar in cancer and non-cancer groups, the mean pain score at $24^{\text {th }}$ and $72^{\text {nd }}$ hours were significantly different. The mean pain score at $24^{\text {th }}$ and $72^{\text {nd }}$ hours was also found to be significantly less in non-cancer patients compared to cancer patients. The results suggest that although considerable pain relief was observed in both the groups, it was relatively rapid in non-cancer patients. This difference can be attributed to the nature, as well as the etiologic and inter-patient variability of diseases among the two groups. Cancer pain is more chronic in nature, moreover, since most of the cancer patients attending Pain and Palliative belonged to the metastatic stage 4, more crucial pain management is required.

The major side effects observed in our study population were constipation (89.2\%), fatigue (37.4\%), dry mouth $(36 \%)$ and nausea/vomiting (23\%). This outcome was similar to other related studies. In an evidence based report published by Cherny et al., the most frequently seen side effects of morphine were nausea/vomiting (15-30\%), constipation (40-70\%), sedation (20-60\%) and pruritus (2-10\%), while myoclonus, abdominal pain, respiratory depression and cognitive impairments were some of the less experienced ADRs. Some of the rare side effects included were hallucination, delirium, sweating and hyperalgesia etc [26]6. On comparing ADRs in the cancer and non-cancer groups, constipation was found to be the most possible ADR of morphine in both the groups, followed by fatigue, nausea/ vomiting, dry mouth and sleepiness. Although both groups exhibited ADRs, there was significantly higher incidence in cancer patients as compared to non-cancer patients.

On the basis of intensity, a higher proportion of cancer patients experienced severe nausea/vomiting (7.7\%) and sleepiness $(5.7 \%)$, whereas itching was slightly more prevalent in non-cancer patients $(2.9 \%)$. Constipation, fatigue and dry mouth were exhibited equally by both the groups. Other rare ADRs like sweating, dizziness, abdominal pain and urinary retention were exhibited only in a few patients. In addition, hallucination and lack of appetite were only experienced among cancer patients. The Naranjo Causality assessment scale was used to ascertain the causal relationship between the morphine therapy and the concurrent ADRs seen in patients. However, due to lack of de-challenge and re-challenge phenomenon, most of the ADRs were established to have a possible causal relation rather than definite. These variations in ADRs could be explained by the differences in their comorbid conditions, aetiology, adjuvant medications, as well as inter-patient variability.

\section{CONCLUSION}

In our study, the effectiveness of immediate release oral morphine was ascertained in the sample population and adequate pain relief was found in the majority of patients. On comparison between cancer and non-cancer groups, considerable pain relief was observed in both the groups, though it was relatively rapid in non-cancer patients - highlighting the fact that oral morphine can be used as an effective short term therapy in non-cancer patients.

The prescribing pattern of oral morphine was found to be in accordance with the general prescribing guideline, and a similar prescription pattern was followed in both cancer and non-cancer groups. However, switch over therapy from oral morphine and dose escalation were more predominant among the cancer group. While analysing the side effect profile of patients on oral morphine, the most commonly seen ADRs were constipation, nausea/vomiting, dry mouth and fatigue - with a higher incidence in the cancer group. The severity of sleepiness and nausea/vomiting was predominant in cancer group, while it was itching in the noncancer group.

\section{STRENGTH}

Our study could serve as an outline for future research among various subgroup populations with different co morbidities and can act as an essential framework for managing pain in such situations, as well as assist the physician in 
optimizing their pharmacotherapy. No similar published literatures on subgroups of Indian population regarding prescribing pattern were published prior to ours.

\section{CONFLICT OF INTEREST}

The authors declare that there is no conflict of interest. All authors have equally contributed to the above work.

\section{ETHICAL APPROVAL}

1. The Ethical Committee of Amrita Institute of Medical Sciences, Amrita Vishwa Vidyapeetham, Kochi, Kerala.

2. Approval received on 14/10/2017.

3. IEC-AIMS-2017-PHARM-369.

\section{ORCID iDs}

Anila K N (Dhttps://orcid.org/0000-0003-2593-9623

\section{REFERENCE}

1. Katz N. The impact of pain management on quality of life. J Pain Symptom Manage. 2002;24(1):S38-S47.

2. Kitzes JA, Domer T. Palliative Care. J Pain Palliat Care Pharmacother. 2004;17(3):201-10.

3. Palat G, Venkateswaran C. Progress in palliative care in India. Progress in Palliative Care. 2012;20(4):212-8.

4. Hanks GW, Conno F, Cherny N, Hanna M, Kalso E, McQuay, et al. Morphine and alternative opioids in cancer pain: the EAPC recommendations. Br J Cancer. 2001;84:587-93.

5. Thirlwell MP, Sloan PA, Maroun J, Boos J, Besner JG, Stewart JH, et al. Pharmacokinetics and clinical efficacy of oral morphine solution and controlled-release morphine tablets in cancer patients. Cancer. 1989;63(11):2275-83.

6. Rajagopal M R, Venkateswaran C. Palliative Care in India: Successes and Limitations. J Pain Palliat Care Pharmacother. 2003;17 (3):121-8.

7. Breivik H, Cherny N, Collet B, de Conno F, Filbert M, Foubert AJ, et al. Cancer - related pain: a pan-European survey of prevalence, treatment, and patientattitudes. Ann Oncol. 2009;20(8):1420-33.

8. Brown J, Setnik B, Lee K, Cleveland JM, Roland CL, Wase L, et al. Effectiveness and safety of morphine sulfate extended-release capsules in patients with chronic, moderate-to-severe pain in a primary care setting. J Pain Res. 2011;4:373-84.

9. Chou R, Fanciullo GJ, Fine PG, Adler JA, Ballantyne JC, Davies P, et al. Clinical guidelines for the use of chronic opioid therapy in chronic non cancer pain. J Pain. 2009;10(2):113-30.
10. Penning-van Beest F, van der Haak P, Klok RM, Prevoo YFDM, van der Peet D, Herings RMC. Quality of life in relation to constipation among opioid users. J Med Econ. 2010;13(1):129-35.

11. Pappagallo M. Incidence, prevalence and management of opioid bowel dysfunction. Am J of Surg. 2001;182(5):s11-s18.

12. Elumelu T, Abdus Salam A, Soyanwoo O, Adenipekun A. Pattern of morphine prescription by doctors in a Nigeria tertiary hospital. Nigerian J Clin Pract. 2012;15(1):27-9.

13. Barathi B. Oral morphine prescribing practices in severe cancer pain. Indian J Palliat Care. 2009;15 (2):127.

14. Mercadante S, Berchovich M, Casuccio A, Fulfaro F, Mangione S. A prospective randomized study of corticosteroids as adjuvant drugs to opioids in advanced cancer patients. Am J Hosp Palliat Care. 2007;24(1):13-9.

15. Schug S, Sidebotham D, McGuinnety M, Thomas J, Fox L. Acetaminophen as an adjunct to morphine by patient-controlled analgesia in the management of acute postoperative pain. Anesth Analg. 1998;87(2):368-72.

16. Breitbart W. Psychotropic adjuvant analgesics for pain in cancer and AIDS. Psycho-Oncology. 1998;7(4):333-45.

17. Watson CP.Antidepressant drugs as adjuvant analgesics. J Pain Symptom Manage. 1994;9(6):392-405.

18. Reddy S, Patt RB. The benzodiazepines as adjuvant analgesics. J Pain Symptom Manage. 1994;9(8):510-4.

19. Matoba M. Use of morphine and adjuvant drugs according to the condition. Eur J Pain. 2001;5(SA):59-62.

20. Patt RB, Proper G, Reddy S. The neuroleptics as adjuvant analgesics. J Pain Symptom Manage. 1994;9(7):446-53.

21. Caraceni A, Zecca E, Martini C, de Conno F. Gabapentin as an adjuvant to opioid analgesia for neuropathic cancer pain. J Pain Symptom Manage. 1999;17(6):441-5.

22. Khan MI, Walsh D, Brito-DellanN.Opioid and adjuvant analgesics: compared and contract. Am J Hosp Palliat Care. 2011;28(5):378-83.

23. Elliott TE, Elliott BA. Physician attitudes and beliefs about use of morphine for cancer pain. J Pain Symptom Manage. 1992;7(3):141-8.

24. Klepstad P, Rakvag T, Kaas S, Holthe M, Dale O, Borchgrevink PC, et al. The $118 \mathrm{~A}>\mathrm{G}$ polymorphism in the human mu-opioid receptor gene may increase morphine requirements in patients with pain caused by malignant disease. Acta Anaesthesiol Scand. 2004; 48(10):1232-9.

25. Tywcross R, Miller M. Palliative care. In: Oxford textbook of medicine 4e. Warrell DA, Cox TM, Firth JD (eds). Oxford: Oxford University Press; 2003:1397-407.

26. Cherny N, Ripamonti C, Pereira J, Davis C, Fallon M, McQuay H, et al. Strategies to manage the adverse effects of oral morphine: an evidence-based report. J Clin Oncol. 2001;19(9):2542-54. 